\title{
Rupatadine Treatment Is Associated with Atherosclerosis Worsening and Altered T Lymphocyte Recruitment
}

\author{
Marco Busnelli ${ }^{1, *}$ Stefano Manzini ${ }^{1, *}$ Alice Colombo ${ }^{1}$ Fabrizia Bonacina ${ }^{1}$ Giuseppe D. Norata ${ }^{1}$ \\ Elsa Franchi ${ }^{1}$ Silvia Castiglioni ${ }^{1}$ Christos Andronis ${ }^{2}$ Eftychia Lekka ${ }^{2}$ Eugenio Scanziani ${ }^{3,4}$ \\ Giulia Chiesa ${ }^{1}$
}

${ }^{1}$ Department of Pharmacological and Biomolecular Sciences, Università degli Studi di Milano, Milano, Italy

2 Biovista, Athens, Greece

${ }^{3}$ Mouse and Animal Pathology Laboratory, Fondazione UniMi, Milano, Italy

${ }^{4}$ Department of Veterinary Medicine, Università degli Studi di Milano, Milano, Italy

Thromb Haemost 2022;122:853-856.

Rupatadine, an $\mathrm{N}$-alkyl pyridine derivative (8-chloro-11[1-[(5-methyl-3-pyridyl)methyl]-4-piperidyliden]-6,11dihydro-5H-benzo[5,6]cyclohepta[1,2b]pyridine), is a nonsedating, second-generation antihistamine and plateletactivating factor (PAF) antagonist currently employed for the treatment of allergies. ${ }^{1}$

Rupatadine is clinically effective in relieving symptomatic seasonal and perennial allergic rhinitis and it is well tolerated. ${ }^{2,3}$ It displays a robust antagonistic activity toward histamine $\mathrm{H}_{1}$ receptors at subnanomolar concentration in vitro, and also prevents mast cell degranulation. ${ }^{1}$ Additionally, it has also been shown to possess a PAF receptor antagonist activity, achieved at submicromolar concentration in vitro. ${ }^{4}$ Finally, rupatadine is able to reduce the recruitment of macrophages, eosinophils, basophils, and neutrophils, and to inhibit platelet aggregation, ${ }^{5,6}$ all features that could be favorably exploited against atherosclerosis development.

Given the pleiotropic anti-inflammatory effects that rupatadine exerts, in this study we assessed the potential beneficial effect of chronic rupatadine treatment on atherosclerosis development. To this aim, similarly to what we did in analogous studies, ${ }^{7,8}$ rupatadine was administered with a high-fat diet (adjusted calories $42 \%$ from fat, $0.2 \%$ cholesterol) to $15 \mathrm{Apoe}^{-/-}$female mice at the highest tolerated dose

* These authors equally contributed to this work.

received

March 1, 2021

accepted after revision

July 19, 2021

published online

October 25, 2021
Address for correspondence Giulia Chiesa, PhD, Dipartimento di Scienze Farmacologiche e Biomolecolari, Università degli Studi di Milano, via Balzaretti 9, Milano 20133, Italy

(e-mail: giulia.chiesa@unimi.it).

Marco Busnelli, PhD, Dipartimento di Scienze Farmacologiche e Biomolecolari, Università degli Studi di Milano, via Balzaretti 9, Milano 20133, Italy (e-mail: marco.busnelli@unimi.it).

$(170 \mathrm{mg} / \mathrm{kg}$ diet). The treatment lasted for 12 weeks. Atherosclerosis development, as well as possible systemic effects and impact on the lipid profile were evaluated and compared with those in $\mathrm{Apoe}^{-/-}$-untreated mice (-Supplementary Fig. S1, available in the online version).

The treatment did not significantly affect daily food intake (control: $0.106 \pm 0.008 \mathrm{~g} / \mathrm{g}$ body weight; rupatadine: $0.105 \pm 0.007 \mathrm{~g} / \mathrm{g}$ body weight, $p=0.87$ ), water intake (control: $0.147 \pm 0.01 \mathrm{~mL} / \mathrm{g}$ body weight; rupatadine: $0.142 \pm 0.02$ $\mathrm{mL} / \mathrm{g}$ body weight, $p=0.28$ ), or body weight (control: $25.23 \pm 0.85 \mathrm{~g}$; rupatadine: $25.81 \pm 1.77 \mathrm{~g}, p=0.28$ ). No significant differences between groups were also found in the liver, spleen, heart, and kidney weight (-Supplementary Fig. S2, available in the online version).

Moreover, plasma total cholesterol (control: $880.6 \pm$ $124.7 \mathrm{mg} / \mathrm{dL}$; rupatadine: $838.7 \pm 142.1 \mathrm{mg} / \mathrm{dL}, p=0.40$ ) and triglyceride (control: $160.6 \pm 29.7 \mathrm{mg} / \mathrm{dL}$; rupatadine: $181.0 \pm$ $53.1 \mathrm{mg} / \mathrm{dL}, p=0.21$ ) levels were comparable between groups (-Supplementary Fig. S2, available in the online version).

To perform an all-round characterization of rupatadine treatment on the $\mathrm{Apoe}^{-/-}$model, we extensively reviewed a broad panel of histological features across several organs. The hepatic inflammatory status-parenchymal/perivasal hepatic infiltrates and subintimal hepatic macrophageswas overall comparable between groups. The glycogen deposition and steatosis degree in the liver were-as expected-

\footnotetext{
(C) 2021. The Author(s).

This is an open access article published by Thieme under the terms of the Creative Commons Attribution-NonDerivative-NonCommercial-License, permitting copying and reproduction so long as the original work is given appropriate credit. Contents may not be used for commercial purposes, or adapted, remixed, transformed or built upon. (https://creativecommons.org/ licenses/by-nc-nd/4.0/) Georg Thieme Verlag KG, Rüdigerstraße 14, 70469 Stuttgart, Germany
} 


\section{A}

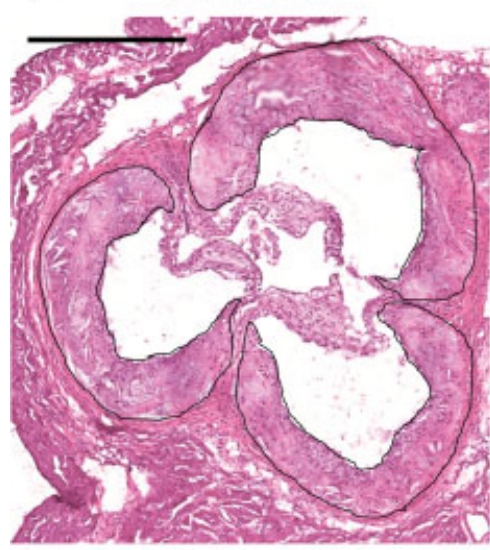

B

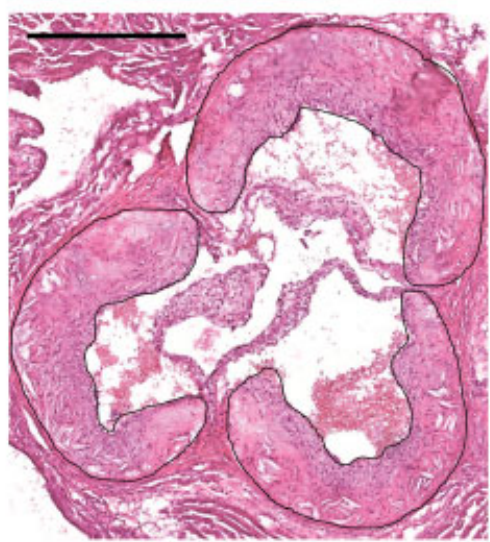

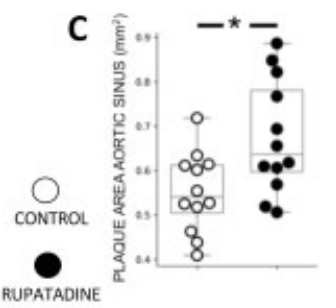

$\mathbf{E}$

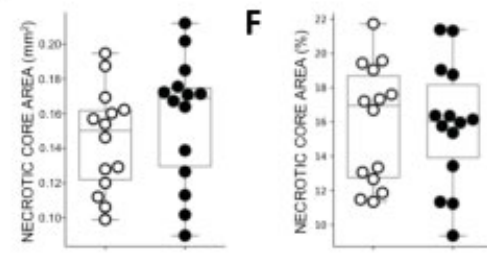

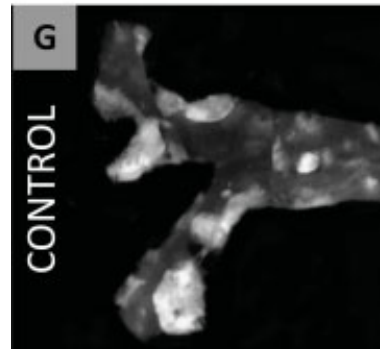

Aortic arch

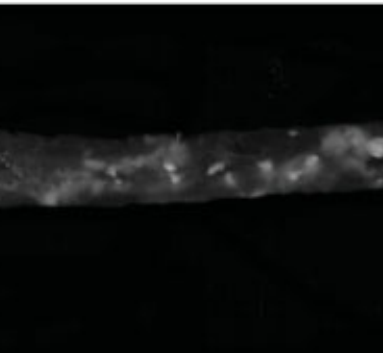

Thoracic aorta

\section{Abdominal aorta}
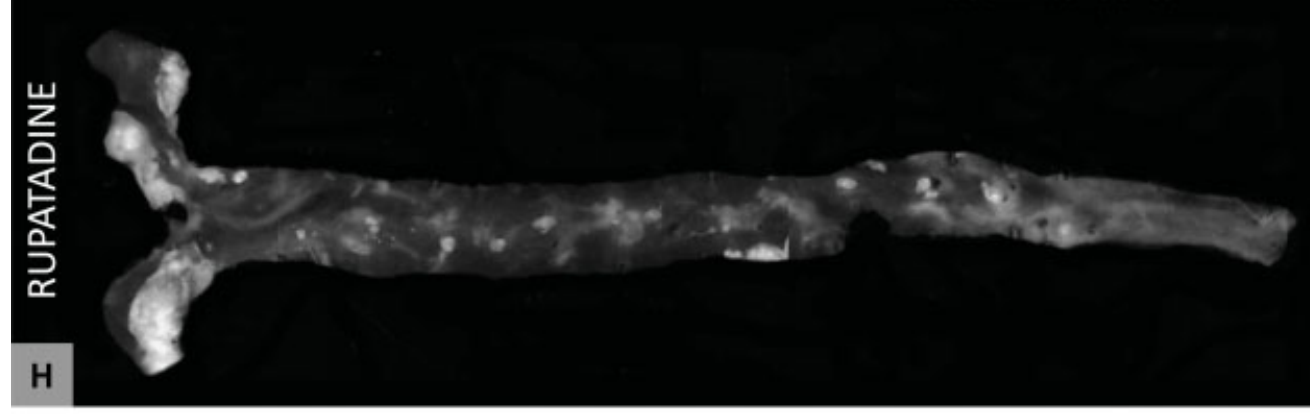

Fig. 1 Atherosclerosis evaluation. Representative hematoxylin \& eosin photomicrographs of aortic sinuses ( $n=15$ per group, bar length $=500 \mu m)(A, B)$. Box plot of aortic sinus values showing a significantly increased plaque development in rupatadine-treated mice (C). Comparable area of the aortic sinus (D) and necrotic core extension (E, F) in plaques from both groups. Representative image of whole aortas ( $n=15$ per group), prepared with the en face technique $(\mathbf{G}, \mathbf{H})$. Box plots of plaque extent (percentage over entire area) in the aortic arch (I), thoracic (J), and abdominal aorta (K). Only in the aortic arch of rupatadine mice, a tendency toward an increase in plaque size was observed. Statistically significant differences were determined by unpaired two-tailed Student's $t$-test. ${ }^{*} p=0.011$.

likewise comparable between groups. In the kidney, glomerular lipidosis, a condition commonly found in $\mathrm{Apoe}^{-1-}$ mice, characterized by the presence of large foamy macrophages within the glomerulus, ${ }^{7,8}$ was not influenced by rupatadine treatment. In lung, the presence of mast cells in the peribronchial and perivascular regions was comparable (-Supplementary Figs. S3-\$5, available in the online version).

Spleens were comparable in terms of hemopoiesis and follicular hyperplasia, almost absent or present to a very slight degree in a small number of samples. In the lymph node, the accumulation of foamy macrophages was similar in both groups. Follicular hyperplasia, the presence of cholesterol crystals and sinus ectasia were almost absent in all samples of both groups (-Supplementary Figs. S3 and \$4, available in the online version).
Atherosclerosis development was assessed in the aortic sinus and in the whole aorta. ${ }^{9,10}$ Unexpectedly, the pharmacological treatment did result in an increased atherosclerotic plaque development at the aortic sinus (-Fig. 1A-C). The total aortic sinus area was comparable in the two groups (-Fig. 1D). Plaques were characterized by comparable necrotic core area ( - Fig. 1E, F), extracellular matrix content ( - Fig. 2A-D), area occupied by neutral lipids ( - Fig. 2E-H) and macrophage amount (-Fig. 2l-L), in terms of both absolute values and percentage composition.

The increase in the aortic sinus plaque area by rupatadine treatment of approximately $22 \%(0.675 \pm 0.129$ in rupatadine vs. $0.551 \pm 0.089 \mathrm{~mm}^{2}$ in control; $p=0.012$ ) was partly confirmed in the aortic arch, the segment closer to the aortic sinus, where a similar-although nonsignificant-increase of approximately $12 \%$ was observed in rupatadine mice ( $36.56 \pm 7.15$ in 

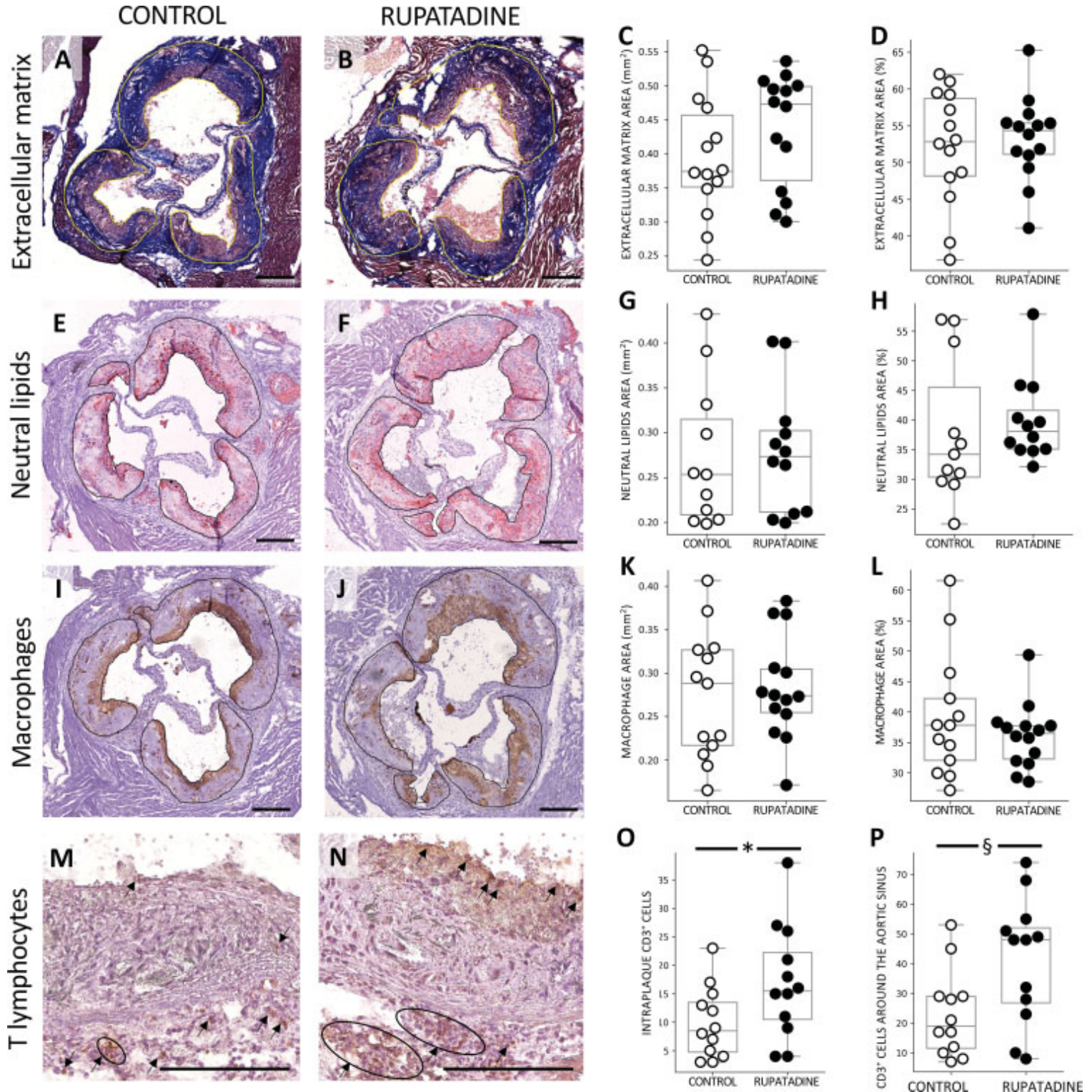

Fig. 2 Histological and immunohistochemical characterization of atherosclerotic plaques at the aortic sinus. Representative photomicrographs of sections stained with Masson's trichrome to highlight extracellular matrix (A-D). Deposition of neutral lipids is revealed by O.R.O. staining (E-H). Plaque macrophage content, assayed with a macrophage-specific immunohistochemistry (anti-Mac2 antibody; I-L). An increased count of CD3 ${ }^{+} \mathrm{T}$ lymphocytes, both as single cells (arrows) and clusters (circles), was observed in the atherosclerotic plaque as well as in the myocardium immediately surrounding the aortic sinus of rupatadine versus control mice (M-P). ${ }^{*} p=0.048,{ }^{\S} p=0.022$. Bar length $=250 \mu \mathrm{m}$. Statistically significant differences were determined by unpaired Student's t-test (C, D, K, L, O, P) or by unpaired Mann-Whitney's U-test (G, H) based on the data distribution (assayed on residuals by Shapiro-Wilk normality test).

rupatadine vs. $32.82 \pm 6.30 \%$ in control; $p=0.13$; - Fig. 1G-I). Plaque development was instead comparable in the thoracic and abdominal segments between the two groups ( - Fig. 1), K).

Circulating immunoglobulin E levels were not significantly modified by the treatment (-Supplementary Fig. S6, available in the online version). No mast cells were detected in plaques and a comparable number of mast cells was observed in the myocardial parenchyma of the two groups. Interestingly, in rupatadine-treated mice, a reduced amount of mast cells was detected in the adventitia immediately surrounding the aortic sinus ( - Supplementary Fig. S7, available in the online version). It has been shown that rupatadine inhibits mast cell degranulation, ${ }^{11}$ thus reducing the release of chemoattractant molecules including leukotriene B4, ${ }^{12,13}$ able to recruit more mast cell progenitors to the site of inflammation. We hypothesize that, in the group of treated mice, rupatadine reduced the enrollment of mast cells around the aortic sinus through this mechanism.

Albeit unexpected, the results on atherosclerosis seem to fall partly in line with a previous report on two other antihistamine molecules, cetirizine and fexofenadine, ${ }^{14}$ administered at different doses to Apoe ${ }^{-/-}$mice. At a lower concentration, both compounds significantly augmented plaque deposition in the aortic sinus and aorta of mice, an 
effect that was completely abolished at a higher dosage. Both treatments had no effect on the number of macrophages and T lymphocytes. ${ }^{14}$ In the present study, a similar finding was obtained for macrophages; conversely, rupatadine-treated Apoe $^{-/-}$mice showed a $70 \%$ increase in the amount of $\mathrm{T}$ lymphocytes infiltrating the plaque and a $80 \%$ increase in the amount of $\mathrm{T}$ lymphocytes within the myocardial parenchyma around the aortic sinus (-Fig. $\mathbf{2 M - P}$ ).

Several evidences from the literature indicate that $\mathrm{T}$ cells express $\mathrm{H}_{1}, \mathrm{H}_{2}$, and $\mathrm{H}_{4}$ histamine receptors. ${ }^{15,16}$ We tested in vitro a possible direct effect of rupatadine on $\mathrm{T}$ lymphocytes (-Supplementary Figs. 58-S10, available in the online version). Rupatadine did not affect cell proliferation, nor CD4/CD8 polarization, a finding also supported by the specific staining performed on lymphoid organs (-Supplementary Fig. S11, available in the online version). Conversely, rupatadine promoted the polarization of $C D 4+$ lymphocytes toward $\mathrm{T}_{\mathrm{H}} 1$ and $\mathrm{T}_{\mathrm{H}} 2$ subsets, suggesting an effect on $\mathrm{T}$ cell activation. $\mathrm{T}_{\mathrm{H}} 1$ cells are known to play proatherogenic functions, whereas the impact of $\mathrm{T}_{\mathrm{H}} 2$ in atherosclerosis is still controversial. ${ }^{17,18}$ Altogether these results can partly explain the observed effect of rupatadine on atherosclerosis development.

In conclusion, rupatadine was shown to affect plaque progression in Apoe ${ }^{-l-}$ mice fed with high-fat diet-a widespread, well characterized, but extreme atherosclerosis model. The impact of $\mathrm{H}_{1}$ antihistamine on cardiovascular disease in humans has been scarcely explored. Although we cannot directly translate our results to a clinical condition of established atherosclerotic disease, taken together our data suggest a cautionary survey of patients regularly taking $\mathrm{H}_{1}$ antihistamine for the treatment of seasonal or chronic illnesses, especially if in the presence of predisposing conditions.

\section{Author Contributions}

M.B.: conceptualization, investigation, writing: original draft, writing: review and editing; Stefano Manzini: investigation, formal analysis, writing: review and editing, visualization; Alice Colombo: investigation; F.B.: investigation; G.D.N.: investigation, resources; E.F.: investigation; Silvia Castiglioni: investigation; C.A.: conceptualization; E.L.: conceptualization; E.S.: investigation; Giulia Chiesa: conceptualization, resources, writing: review and editing, project administration, funding acquisition.

\section{Funding}

This work was funded by the European Community's Seventh Framework Programme (FP7/2012-2017) RiskyCAD, grant no. 305739 (G.C.), "Post-Doctoral Fellowship 2021" by "Fondazione Umberto Veronesi" 2021-442 (F.B.), PRIN 2017K55HLC (G.D.N.), and by grants from MIUR Progetto Eccellenza.

\section{Conflict of Interest}

C.A. and E.L. are senior investigators at Biovista, Athens, Greece. All other authors declare no competing interests.

\section{Acknowledgments}

We are grateful to Mrs. Elda Desiderio Pinto for administrative assistance. Part of this work was performed at NOLIMITS, an advanced imaging facility established by the Università degli Studi di Milano.

\section{References}

1 Merlos M, Giral M, Balsa D, et al. Rupatadine, a new potent, orally active dual antagonist of histamine and platelet-activating factor (PAF). J Pharmacol Exp Ther 1997;280(01):114-121

2 Church MK. Efficacy and tolerability of rupatadine at four times the recommended dose against histamine- and platelet-activating factor-induced flare responses and ex vivo platelet aggregation in healthy males. Br J Dermatol 2010;163(06):1330-1332

3 Demoly P, Chiriac AM, Berge B, Rostin M. Reasons for prescribing second generation antihistamines to treat allergic rhinitis in real-life conditions and patient response. Allergy Asthma Clin Immunol 2014;10(01):29

4 Mullol J, Bousquet J, Bachert C, et al. Rupatadine in allergic rhinitis and chronic urticaria. Allergy 2008;63(Suppl 87):5-28

5 Muñoz-Cano RM, Casas-Saucedo R, Valero Santiago A, Bobolea I, Ribó P, Mullol J. Platelet-activating factor (PAF) in allergic rhinitis: clinical and therapeutic implications. J Clin Med 2019;8(09): 1338

6 Picado C. Rupatadine: pharmacological profile and its use in the treatment of allergic disorders. Expert Opin Pharmacother 2006;7 (14):1989-2001

7 Busnelli M, Manzini S, Bonacina F, et al. Fenretinide treatment accelerates atherosclerosis development in apoE-deficient mice in spite of beneficial metabolic effects. Br J Pharmacol 2020;177 (02):328-345

8 Manzini S, Busnelli M, Parolini C, et al. Topiramate protects apoEdeficient mice from kidney damage without affecting plasma lipids. Pharmacol Res 2019;141:189-200

9 Busnelli MManzini S, Chiara M, et al. Aortic gene expression profiles show how ApoA-I levels modulate inflammation, lysosomal activity, and sphingolipid metabolism in murine atherosclerosis. Arterioscler Thromb Vasc Biol 2021;41(02): 651-667

10 Busnelli M, Manzini S, Hilvo M, et al. Liver-specific deletion of the Plpp3 gene alters plasma lipid composition and worsens atherosclerosis in apoE ${ }^{-/-}$mice. Sci Rep 2017;7:44503

11 Mullol J, Bousquet J, Bachert C, et al. Update on rupatadine in the management of allergic disorders. Allergy 2015;70(Suppl 100): $1-24$

12 Krystel-Whittemore M, Dileepan KN, Wood JG. Mast cell: a multifunctional master cell. Front Immunol 2016;6:620

13 Collington SJ, Williams TJ, Weller CL. Mechanisms underlying the localisation of mast cells in tissues. Trends Immunol 2011;32(10): 478-485

14 Raveendran VV, Smith DD, Tan X, et al. Chronic ingestion of H1antihistamines increase progression of atherosclerosis in apolipoprotein E-/- mice. PLoS One 2014;9(07):e102165

15 Thangam EB, Jemima EA, Singh $\mathrm{H}$, et al. The role of histamine and histamine receptors in mast cell-mediated allergy and inflammation: the hunt for new therapeutic targets. Front Immunol 2018;9:1873

16 Kmiecik T, Otocka-Kmiecik A, Górska-Ciebiada M, Ciebiada M. T lymphocytes as a target of histamine action. Arch Med Sci 2012;8 (01):154-161

17 Saigusa R, Winkels H, Ley K. T cell subsets and functions in atherosclerosis. Nat Rev Cardiol 2020;17(07):387-401

18 Wolf D, Ley K. Immunity and inflammation in atherosclerosis. Circ Res 2019;124(02):315-327 